\title{
Comparing Strategic Concepts, A New Strategic Mindset and Coping with an Ever-Growing Toolbox
}

\section{Haron A*}

Higher Colleges of Technology, Sharjah, United Arab Emirates

\section{Introduction}

Whenever a commercial enterprise is founded, it either directly or indirectly employs a specific business model that defines the design or architecture of the value creation, provision, and capture mechanisms it employs [1]. The spirit of a business model is in defining the method by which the enterprise delivers value to customers, tempts customers to pay for value, and converts those payments to profit [2]. It thus reflects management's assumption about what customers want, how they want it, and how the enterprise can establish to best meet those needs, get rewarded for doing so, and make a profit [3]. This reflects the significance of business models and explores their connections with business strategy, innovation management, and economic philosophy [4].

"How are you going to succeed in the period ahead?" That's the key question behind developing strategy [5]. To win at anything meaningful, you need a game plan. Professional sports-teams know this, and this idea relates to your organization, your division, your team, and even to yourself as a person [6]. To be prosperous means knowing how to use your endowment and assets to best advantage, and it's challenging to "win" if you don't have this game-plan in place [7]. Fernandes argured that identifying your unique competences, and understanding how to use these to your advantage while minimizing threats are two important parts of planning a corporate strategy.

An approach to incorporate long-term goals within the shortterm operation optimization model is crucial [8]. Two contradictory objectives for the management of many organisations. A short term optimization models are used to derive long-term operation strategies. With the time limit of operation for the short-term optimization model kept equivalent to a single time-step of the long-term optimization model, the optimum end results derived from the long-term model are incorporated as constraints within the short-term model [3].

Strategy communication is regularly not given the attention that it deserves [9]. Organizations need to deal with this issue systematically so as to convey to the people concerned the intended message [10]. People need to be given information and delivered tools and techniques of understanding the information so that they are able to do a better job [11].

Many people are familiar with controversies over defective products that have swirled around in the world media over the past two decades. However, few have had the opportunity to examine the communication strategies and structure of the companies involved and their ability to deal with the controversy [6]. This illuminates the role strategy communications to all stakeholders, not only from the operational or public relations perspectives, but also an important component of strategy execution and success [12].

The significance of an ongoing process for evaluating execution can't be exaggerated [13]. Contemplate how even a single, timely modification in execution can pay big dividends, for example: A \$300 million professional services company was chasing a growth strategy designed to increase firm incomes significantly. In accepting the strategy, they also introduced a decision-making process consisting of a monthly strategy meeting between the core team of CEO, COO, and CFO. In these conferences, the executives inspected external research, internal progress alongside their strategic plan, and financial results. External research showed radically increased competition in the company's market. Internal progress measured by lead-generation, sales calls, and contracts created, showed that the company's 22 offices around the world were all vigorously pursuing business. However, revenue indicators weren't being achieved; and if the company persistent on its present course, it would fall short of its objectives. Instead of finishing, long after the fact, that times were harsh because of increased competition and that the growth strategy was improbable, the managers looked more carefully at strategy execution. They found that offices fixated on building business with existing clients were achieving growth targets, and generating higher profits, more often than offices that focused more on pursuing new clients. By swiftly refocusing all offices on increasing share of customer (or market share), the firm was soon hitting revenue and profit indicators. This reflects the importance of looking at all the components that make up the constellation of mutually aligned behaviors which are applied by most organisations and to give all the components regardless of how seemingly small or insignificant one of them is the same level of attention and respect [14] (Table 1).

Prompt changes and ambiguity in business environments have extended the decision-making role of the employee and the need for strategic thinking [8]. One of the competencies for successful business leaders is strategic thinking skills, including "critical thinking, out of the box thinking, abstract thinking, academically guided thinking, and ground-breaking thinking [15]. According to Managers must be able to think strategically and creatively to implement organizational change initiatives. One of the keys to becoming a great leader is to continuously improve strategic thinking skills. This competency will enable mangers and employees to question, reflect, expect, forecast, and make strategic decisions [3].

\section{A New Strategic Mindset}

The word "strategy" can summon images of corporate boardrooms and battleground commanders. However, a strategic mindset does not require infinite committee meetings or enormous resources. The effort can be launched in a short period and adopted over time [16]. Ultimately, a strategic mindset means you have a vision for your business past year end, you can imagine 2, 5 or even 15 years out [17]. That means setting wider goals, nevertheless still with time frames and

*Corresponding author: Haron A, Higher Colleges of Technology, Sharjah, United Arab Emirates, Tel: 971505072291; E-mail: abbottjharon@gmail.com

Received December 05, 2014; Accepted April 08, 2015; Published April 16, 2015

Citation: Haron A (2015) Comparing Strategic Concepts, A New Strategic Mindse and Coping with an Ever-Growing Toolbox. J Mass Communicat Journalism 5: 254 doi:10.4172/2165-7912.1000254

Copyright: (c) 2015 Haron A. This is an open-access article distributed under the terms of the Creative Commons Attribution License, which permits unrestricted use, distribution, and reproduction in any medium, provided the original author and source are credited. 


\begin{tabular}{|c|c|c|c|c|c|c|c|c|}
\hline $\begin{array}{c}\text { Criteria } \\
\text { Strategic Concepts and Tools }\end{array}$ & $\begin{array}{c}1 \\
\text { System }\end{array}$ & $\begin{array}{c}2 \\
\text { Environment }\end{array}$ & $\begin{array}{c}3 \\
\text { Rela-tions }\end{array}$ & $\begin{array}{c}4 \\
\text { Power }\end{array}$ & $\begin{array}{c}5 \\
\text { Direc-tion }\end{array}$ & $\begin{array}{c}6 \\
\text { Thrust Energy }\end{array}$ & $\begin{array}{c}7 \\
\text { Sustainability }\end{array}$ & $\begin{array}{c}8 \\
\text { Human Behavi our }\end{array}$ \\
\hline Ansoff's matrix & & & $\mathrm{x}$ & & $\mathrm{x}$ & & $x$ & \\
\hline Core Competencies & $\mathrm{x}$ & & & & & & $x$ & $\mathrm{x}$ \\
\hline Environmental analysis [STEP, PEST, SERF, etc.]] & $\mathrm{x}$ & $\mathrm{X}$ & $\mathrm{X}$ & $\mathrm{X}$ & $\mathrm{x}$ & $\mathrm{x}$ & & \\
\hline McGregor's theory $\mathrm{x}$ - theory $\mathrm{y}$ & & & & & & $x$ & & $\mathrm{X}$ \\
\hline SWOT analysis & $x$ & $x$ & $x$ & $x$ & & & & \\
\hline
\end{tabular}

Table 1: Showing strategic concepts and tools.

relevant metrics. In addition, you can relate day-to-day decisions both to instantaneous business impact and progress headed for those longterm goals. That idea stands repeating, a strategic mindset gets you thinking about the influence of your decisions on your business today and in its future [17].

Senior managers need improved strategic mindset to navigate our unevenly globalized world. Although a wide range of metrics display that a small percent of economic activity is truly global, executives excessively embrace visions of unbounded opportunities in a world without borders, where spaces and dissimilarities no longer matter [17].

Rooted new mindsets correct a misunderstanding reinforced by conventional ones: that the world looks the similar regardless of the spectator's vantage point or purpose. In the real world, however, geographic expanse and variances in culture and policy matter. To better reflect this reality, rooted new mindsets depict the world from a specific viewpoint and with a particular purpose in mind [16]. They do so by altering the sizes or positions of countries in relative to a specific home country, while otherwise preserving familiar shapes and spatial associations, which help us fit these new mindsets into our existing mental models [17].

As your new strategic mindset gets your head up and you off of the treadmill or desk, taking original action on the growth actions that will move your business onward, you will find that you can increase this model to make it a perpetual and formal part of your operation. Along the way, you will appreciate knowing that your business will not be the same in ten years, it will have taken great steps toward reaching your vision [17].

\section{Coping with an Ever-Growing Toolbox}

The first tool we have chosen is Asnoff's matrix, it effects relationships because being a marketing planning tool it helps a business determine its product and market growth strategy which will determine the relationship it will have with its competitors. Furthermore, since Asnoff's product/market growth matrix proposes that a business' tries to grow depend on whether it markets new products has an influence on its direction in the future or existing products, which effect its direction in new or existing markets [8].

This study of the SWOT analysis tool shows that the Strengths impact on the company's system by determining the allocation of human and other resources, The Weaknesses the direction the company is heading towards, since it now knows it limitations impact. The company will also use the opportunities to determine the relationships it will have with its surrounding environment to be able to take full advantage of them. Finally the threats will help the organisations to the balance of power within its business environment to know who to avoid its strongest or biggest threats [18].

Core competencies if developed and nurtured will result in a stronger system with in the organisations, because each pert of the system would be operating based on a core competency, in addition, having core competencies will give an organisations a sustainable advantage which will insure its longevity. Finally, no self-respecting organisations would be able to attain any core competency without a healthy respect for correct human behavior in the workplace, which in return becomes an incubator for the development of future core competencies [19].

Moreover, environmental analysis tools help organisations in most if not all of the areas below, especially if your company is planning international expansion, it will help establish a system by knowing what is expected of it in the new market, it will help it understand its business environment by looking at the macro factors in the new market, it will help build relationships when you understand who are your major stakeholders in the new market, it will help you understand the balance of power when you understand who are you main and secondary competitors, it will help you know the future direction of the company by helping you navigate the new market, it will give you a thrust of energy, especially when you know what direction you are heading [3].

Finally, McGregor's theory $\mathrm{x}$ - theory $\mathrm{y}$, is a great tool to manage and propagate great human behaviour in the work place, which would motivate employees to perform to the best of the abilities, which in return will give the organisation thrust of energy to keep achieving its strategic goals and objectives [20].

\section{References}

1. Allio MK (2012) Strategic dashboards: designing and deploying them to improve implementation. Strategy \& Leadership 40: 24-31.

2. Eppler MJ (2000) Conceptual Management Tools: A Guide to Essential Models for Knowledge Workers. Conceptual Management Tools.

3. Wood S (2002) Corporate Strategy. Teaching Business \& Economics 6(3)

4. Teece DJ (2010) Business Models, Business Strategy and Innovation. Long Range Planning 43: 172-194

5. Anca P (2012) Corporate Governance: Principles and Regulations. Journal of Electrical and Electronics Engineering 5: 155.

6. Becker MC (2001) Managing Dispersed Knowledge: Organizational Problems, Managerial Strategies, and Their Effectiveness. Journal of Management Studies 38: 1037-1051.

7. Lavy S, Garcia JA, Dixit MK (2010) Establishment of KPIs for facility performance measurement: review of literature. Emerald Group Publishing Limited 28: 440-464

8. Martinet AC (2010) Strategic planning, strategic management, strategic foresight: The seminal work of $\mathrm{H}$. Igor Ansoff. Technological Forecasting \& Social Change 77: 1485-1487.

9. Minkler AP (1993) The Problem with Dispersed Knowledge: Firms in Theory and Practice. KYKLOS 46: 569-587.

10. Viaene S, Willems J (2007) Corporate Performance Management: Beyond Dashboards and Scorecards. Journal of Performance Management 20: 13-33.

11. Sole D, Edmondson A (2002) Situated Knowledge and Learning. British Journal of Management 13: S17-S34.

12. Chakraborty A, Chuan TK (2013) An empirical analysis on Six Sigma implementation in service organisations. International Journal of Lean Six Sigma 4: 141-170. 
Citation: Haron A (2015) Comparing Strategic Concepts, A New Strategic Mindset and Coping with an Ever-Growing Toolbox. J Mass Communicat Journalism 5: 254. doi:10.4172/2165-7912.1000254

Page 3 of 3

13. Hilb M (2005) New Corporate Governance: from good guidelines to great practice. New Corporate Governance 13: 569-581.

14. Calantonea RJ, Cavusgila ST, Zhao Y (2002) Learning orientation, firm innovation capability, and firm performance. Industrial Marketing Management 31: $515-524$.

15. Anonymous (2001) Towards a Sustainable Future. The Science of the Total Environment 233-237.

16. Jacobson R (2013) CEO Mindset for the Future. Physician Exec 39: 88-91.
17. Massingham P (2013) Cognitive Complexity in Global Mindset. International Journal of Management, 30: 232-248.

18. Căprărescu G, Stancu DG, Aron G (2013) The Swot Analysis Between Myth And Reality. Knowledge horizons 5: 38.

19. Eckerson WW (2011) Performance dashboards.

20. Kopelman RE, Prottas DJ, Davis AL (2008) Douglas McGregor's Theory X and Y: Toward a Construct-valid Measure. Journal of Managerial Issues 20: 255-271. 